\title{
Öğrencilerin Matematikle İlgili Tarihsel Sözlerin Derslerde Kullanımına İlişkin Görüşleri ve Tarihsel Sözlere Yer Verme Durumlari ${ }^{1}$
}

\section{Opinions of Students about the Use of Mathematical Historical Sayings in Classes and Their State of Using Historical Sayings}

\author{
Cemalettin YILDIZ ${ }^{2}$
}

\begin{abstract}
Öz: Bu çalışmada, ortaokul öğrencilerinin matematikle ilgili tarihsel sözlerin derslerde kullanımına yönelik düşüncelerini ve tarihsel sözlere nerelerde yer verdiklerini ortaya çıkarmak amaçlanmıştır. Araştırmada özel durum çalışması yöntemi kullanılmıştır. Çalışmanın verileri yapılandırılmamış gözlem, yarı yapılandırılmış mülakat ve doküman incelemesi yardımı ile toplanmıştır. Araştırma kapsamında ilk olarak matematikle ilgili tarihsel sözlerin kullanıldığ 1 gözlemlenen iki farklı devlet okulunda 34 ders saati gözlem yapılmıştır. Daha sonra, çalışmanın amacı doğrultusunda 17 ortaokul öğrencisi ile mülakatlar gerçekleştirilmiştir. Son olarak, öğrencilerin tarihsel sözleri nerelerde kullandıklarını tespit etmek için doküman incelemesi yapılmıştır. Gözlemlerden ve doküman incelemesinden elde edilen veriler betimsel, mülakatlardan sağlanan veriler ise betimsel ve içerik analizine tabi tutulmuştur. Çalışmanın sonunda, öğrencilerin tarihsel sözlerin matematik dersine ilgiyi arttırdığını, genel olarak tarihsel sözlerden hoşlandıklarını ve sözleri başkaları ile paylaştıklarını ancak bazı tarihsel sözleri anlamada zorlandıklarını ve sözleri yorumlayamadıklarında özgüvenlerinin azaldığını belirttikleri tespit edilmiştir. Ayrıca tarihsel sözlerin öğrencilere matematik derslerinde yeni alternatifler sunduğu belirlenmiş̧ir. Bu alternatiflerin sözleri panolara asma, defterlere not etme, ürün dosyalarının kapaklarına ve tahtalara yazma şeklinde olduğu ortaya çıkmıştır.
\end{abstract}

Anahtar sözcükler: Matematik, tarihsel sözlerin kullanımı, ortaokul ögrencileri

\begin{abstract}
This study aims to reveal the opinions of middle school students about the use of mathematical historical sayings in classes and where they use historical sayings. Case study method was used in the study. The study data were collected with the help of unstructured observation, semi-structured interview, and document examination. Within the scope of the study, an observation of 34 course hours was primarily made at two different public schools where historical sayings were used in mathematics classes. And then interviews were conducted with 17 middle school students according to the
\end{abstract}

\footnotetext{
$1 \mathrm{Bu}$ çalışma, 23-26 Nisan 2015 tarihinde Antalya'da Eğitim ve Bilimde Uluslararası Araştırma Kongresi'nde (International Conference on Research in Education and Science) sunulan bildirinin genişletilmiş halidir.

2 Yrd. Doç. Dr., Giresun Üniversitesi, e-posta: cemalyildiz61@gmail.com
} 
study objective. Finally, a document examination was carried out for the purpose of determining where students were using historical sayings. While the data acquired from observations and document examination were subjected to descriptive analysis; the data acquired from interviews were subjected to descriptive and content analysis. As a result of the study, students stated that historical sayings increased their interest in math classes; they generally liked historical sayings and shared those sayings with others, but had a difficulty in understanding some of the sayings and had a reduced self-confidence when they failed in interpreting the sayings. It was also determined that historical sayings presented new alternatives to students in math classes as; hanging the sayings on panels and writing them down in notebooks, on the covers of product files and boards.

Keywords: Mathematics, use of historical sayings, middle school students

\section{GİRIŞ}

İnsanlar, birbirleriyle ve dış dünyayla olan iletişimlerini kelimelerle ve bu kelimelerin oluşturduğu sözlerle gerçekleştirmektedirler (Yaşar ve Girmen, 2012). Söz, bir toplumun aynasıdır. Kullanılan sözün güzel ve anlamlı olması insanlara birçok güzellik katar. Söz, insanın insanla diyaloğu; insanın insanı kucaklaması ve kuşatmasıdır (Işı1k ve Kopuz, 2005). Söz, bir düşünceyi eksiksiz olarak anlatan kelime, kelam ve laf olarak tanımlanabilir (Türk Dil Kurumu, 2011). Bir duygu veya düşünce anlatılırken bazen onlarca söze gereksinim duyulabilir. Güzel sözler, kuşaktan kuşağa ulaşan en değerli miras ve en anlamlı vasiyettir (Çağlayan, 2006). Fikirleri etkili bir şekilde anlatması sebebiyle bu sözler insanları kuşatır ve insanlar bu sözlerin etki alanından uzun süre kurtulamaz (Işık ve Kopuz, 2005). Bu nedenle, güzel sözler insanlar tarafından sıkça kullanılmaktadır. Kimi zaman birkaç paragrafla anlatılabilecek bir konu, sadece tek bir cümle ile de alıcı durumundaki insanlara kolay bir biçimde aktarılabilir (Yakıncı, Yakında ve Akın, 2013). Bu tür sözleri öğrenmenin, anlamanın ve hayata geçirmenin önemli olduğu söylenebilir.

"Sözlerin her biri, tarihin belli bir dönemini, zamanını veya olayını simgelemektedir. Dolayısıyla, sözler insanları alıp başka mekânlara ve zamanlara götürmektedir. Bazı sözler de önemli insanlar tarafından belli bir olay üzerine söylenmiş, adeta bir slogan gibi popüler hale gelmiş ve insanların dillerine yerleşmiştir” (Atmaca, 2007, s.7-8).

Tarihe mal olmuş nice filozoflar, söz ustaları ve bilim insanları yaşamıştır (Çağlayan, 2006). İnsanlık tarihini etkilemiş bu insanlar, söyledikleri sözlerle yaşadıkları milletlere onurlu bir yer kazandırmışlardır (Ertan, 2012). Özellikle de sözün sahibi, ünlü bir matematikçi, devlet adam1, komutan, bilim insanı veya tarihe yön vermiş ünlü bir kişi ise bu sözler daha da önem kazanmıştır (Atmaca, 2007). Bu insanlar düşünce ve bilgileri ile dünyayı güzelleştiren, süsleyen ve zenginleştiren sözler üretmişlerdir (Ertan, 2012). Onların ifade ettikleri gerçekler, düşünceler ve sözler, çağları aşan birer 1şık gibi günümüze ulaşmıştır (Çağlayan, 2006). Sözlerin faydaları aşağıdaki gibi özetlenebilir: 
•Insanların genel kültür seviyelerini arttırır ve insanlara keyif verir (Atmaca, 2007).

-İnsanlara hayatta daha başarılı olmanın yollarını gösterir (Ertan, 2012).

-Akılda kaldiklarından bilgilerin bu yolla verilmesi daha kolaydır (Yakınc1 vd., 2013).

-Öğrencilerin ilgilerini çekip öğrenmelerini kolaylaştırır. Böylece, bilgilerin kalıcılığg ve derslerin daha zevkli geçmesi sağlanmış olur (Yakıncı vd., 2013).

•Hatırlamayı ve düşünmeyi sağlar (Yakıncı vd., 2013).

-Kimlik oluşumuna ve insanların davranışlarının anlaşılmasına yardımc1 olur (Yakınc1 vd., 2013).

Bir duyguyu, bir düşünceyi kısa ve etkili bir biçimde anlatan, kim tarafindan söylendiği genellikle bilinen cümlelere özdeyiş, özlü söz, vecize, kelam-1 kibar, ibretli söz, aforizma, motto gibi isimler verilmektedir (Yakınc1 vd., 2013). Bu cümleler, matematikte "Tarihsel Sözler (TS)" olarak adlandırılmaktadır (Swetz, 1994). TS'ler, öğrenciler üzerinde önemli derecede etki bırakabilecek ve tarihsel empatinin gelişimine katkıda bulunabilecek bir öğretim materyalidir. TS'ler derslerin akışını tarihi olarak zenginleştirdiklerinden (Swetz, 1994), matematik derslerinde büyük ve önemli görülen bilim insanlarının matematiğe yönelik TS'lerini kullanmak gerekmektedir. Çünkü bu insanların matematikle ilgili TS'leri öğrenciler için rol model olduklarından, bu sözler öğrencileri matematik derslerine hazırlayabilir.

"TS'ler okuyucunun gözüne, dinleyicinin ise kulağına takılmaktadır. İnsanların kendilerini TS'leri söyleyen kişilerin yerine koymaları, insanlara bir tür otorite duygusu vermektedir. TS'ler sınıfta bir düşünceye odaklanmaya ve bir tartışma başlatmaya yardım edebilir. "TS'yi kim söylemiştir?" "TS, ne anlatmak istemektedir?" "TS, niçin söylenmiştir?" Bu ve daha birçok soru matematikle ilişkili TS'lerin öğrenme ortamlarında nasıl kullanılacağını göstermektedir" (Swetz, 1994, s.91).

Öğretim programlarının yenilenmesi ve güncellenmesi ile ders kitaplarında (Alkan, 2007; Aydın ve Beşer, 2009; Bozkurt, Ak, Erdoğan ve Şahin, 2008; Durmuş, 2010; Göğün, 2008; Kaptan, 2009; Karakuyu ve Bağc1, 2014) matematiğe yönelik TS'lerin öneminin arttlğı ve bu hususun derslerde TS'lerden faydalanılması gerektiği sonucunu açığa çıkardığı söylenebilir. İlgili alanyazın incelendiğinde, matematikle ilgili TS'lere yönelik sadece iki çalışmaya (Hatısaru, 2009; Yıldız ve Taşkın, 2011) ulaşılabilmiştir. Hatısaru (2009), ortaöğretim 9. sınıf öğrencilerinin matematiğe yönelik düşüncelerini altı TS yardımıyla tespit etmiştir. Çalışmanın sonunda, öğrenciler matematiğin hayatın ayrılmaz bir parçası olduğunu ve matematik öğrenirken sabırlı olmak gerektiğini dile getirmişlerdir. Benzer şekilde Yıldız ve Taşkın (2011), 8. sınıf öğrencilerinin matematiğe yönelik görüşlerini sekiz TS 
aracılığıyla belirlemişlerdir. Araştırmanın sonunda, öğrencilerin matematiğin sabır gerektiren, gelişen, zevkli ve zor bir bilim olduğunu belirttikleri belirlenmiştir. Görüldüğü gibi, matematikle ilgili TS'lerin sadece ortaokul ve lise öğrencilerinin matematiğe yönelik düşüncelerini açığa çıkarmak için kullanıldı̆̆ı anlaşılmaktadır.

Matematikle ilgili TS'lerin derslerde kullanılması ve gelecek nesillere aktarılması hayati önem taşımaktadır. Bu nedenle, TS'lere matematik derslerinde daha fazla yer verilebilir. Çünkü TS'ler aracılığıyla matematik dersleri daha eğlenceli hale gelebilir; öğrencilerin matematiğe yönelik genel kültür seviyeleri artabilir ve matematiği sevmeleri sağlanabilir. Bu bağlamda, tarihin önemli sözlerini söyleyen insanların matematiğe ilişkin duygu ve düşüncelerini gelecek kuşaklara aktarmak, öğrencilerin bu sözlerle ilgili görüşlerini almak ve bu sözlere matematik derslerinde nerelerde yer verdiklerini belirlemek gerekmektedir. Yapılan alan yazın taraması sonucunda, matematikle ilgili TS'lerin derslerde kullanımına ilişkin öğrenci görüşlerini ve öğrencilerin bu TS'leri nerelerde kullandıklarını konu edinen bir çalışmaya ulaşılamamıştır. Dolayısıyla, alanda bulunan eksikliği giderebileceği ve sonraki araştırmalara kılavzuluk edebileceği düşünülerek bu araştırma yapılmıştır. Benzer şekilde araştırmacılar, öğretmenler ve öğretmen adayları bu çalışmanın bulgularından, sonuçlarından ve önerilerinden TS'lerin matematik derslerinde etkili bir biçimde kullanımına ilişkin önemli bilgiler elde edebilirler.

\subsection{Araştırmanın Amacı}

$\mathrm{Bu}$ çalışmada, ortaokul öğrencilerinin matematik ile ilgili TS'lerin derslerde kullanımına yönelik düşüncelerini ve TS'lere nerelerde yer verdiklerini ortaya çıkarmak amaçlanmaktadır. $\mathrm{Bu}$ amaç doğrultusunda aşağıdaki sorulara yanıt aranmıştır:

1. Ortaokul öğrencilerinin matematik ile ilgili TS'lerin derslerde kullanımına yönelik görüşleri nelerdir?

2. Ortaokul öğrencileri matematik ile ilgili TS'lere nerelerde yer vermektedirler?

\section{YÖNTEM}

$\mathrm{Bu}$ araştırmada nitel yaklaşımına dayalı yöntemlerden biri olan özel durum çalışması yöntemi kullanılmıştır. $\mathrm{Bu}$ yöntem, bireysel yürütülen çalışmalar için uygundur ve seçilen bir konunun ayrıntılı bir biçimde araştırılmasına olanak sağlar (Çepni, 2007). Özel durum çalışması yöntemi gözlem, mülakat ve doküman incelemesi gibi farklı veri toplama tekniklerinin bir arada kullanılmasına imkân verir (Cohen ve Manion, 1994; Çepni, 2007). Çalışmanın az sayıda ortaokul öğrencisi ile yürütülmesi ve bu araştırmada birden fazla veri toplama aracının birlikte kullanılması nedeniyle çalışmada bu yöntem tercih edilmiştir.

\section{1. Çalışma Grubu}


Araştırılan probleme taraf olabilecek kişilerin çeşitliliğini en üst düzeyde ortaya koymak amaciyla (McMillan ve Schumacher, 2006; Yildırım ve Şimşek, 2008) araştırmada maksimum çeşitlilik örneklemesi tercih edilmiştir. Araştırmanın katılımcılarını Trabzon'daki iki farklı devlet ortaokulunda öğrenim gören 17 gönüllü öğrenci oluşturmaktadır. Araştırmaya katılan öğrencilerin isimleri çalışma etiği gereği gizli tutulmuş ve öğrenciler “Ö1, Ö2, Ö3, .., Ö17” olarak kodlanmıştır.

Tablo 1.Öğrencilerin demografik özellikleri

\begin{tabular}{ccccc}
\cline { 2 - 4 } & & Erkek & Kuz & \multirow{2}{*}{ Toplam } \\
\hline \multirow{3}{*}{ Demografik Özellikler } & f & f & \\
\cline { 2 - 4 } Yaş Aralıkları & $9-11$ & 0 & 2 & 2 \\
\cline { 2 - 4 } & $12-14$ & 6 & 8 & 14 \\
\hline \multirow{3}{*}{ Sinıf Düzeyleri } & 15 ve üstü & 0 & 1 & 1 \\
\cline { 2 - 4 } & 6. Sinıf & 2 & 3 & 5 \\
\cline { 2 - 4 } & 7. Sinıf & 2 & 4 & 6 \\
\cline { 2 - 4 } & 8. Sinıf & 2 & 4 & 6 \\
\hline
\end{tabular}

Tablo 1 incelendiğinde, çalışmaya katılan kız öğrenci sayısının erkek öğrenci sayısından daha fazla olduğu görülmektedir. Ayrıca öğrencilerin yaşlarının 12 ile 14 arasında yoğunlaştığı anlaşılmaktadır.

\subsection{Araştırmacının Rolü}

Araştırmacı; çalışma öncesinde, sırasında ve sonrasında öğrencilere araştırmanın amacı ve kendilerinden neler yapmalarının beklenildiğine yönelik bilgiler vermiştir. Araştırmacı, gözlem, mülakat ve doküman incelemesi esnasında kendi ön yargılarını çalışma süresince elde edilen verilerden mümkün olduğunca uzak tutmuş ve tarafsız bir yol izlemiştir.

\subsection{Veri Toplama Araçları ve Uygulama Süreci}

Çalışmada veri toplama araçları olarak yapılandırılmamış gözlemden, yarı yapılandırılmış mülakattan ve doküman incelemesinden yararlanılmıştır. Araştırma boyunca kullanılan sorular ve veri toplama araçları Tablo 2'de verilmiştir:

Tablo 2. Araştırma soruları ve veri toplama araçları

\begin{tabular}{lccc}
$\begin{array}{l}\text { Veri Toplama Araçtarı } \\
\text { Araştırma Soruları }\end{array}$ & Gözlem & Mülakat & $\begin{array}{c}\text { Doküman } \\
\text { Incelemesi }\end{array}$ \\
\hline $\begin{array}{l}\text { 1.Matematikle ilgili TS'lerin derslerde } \\
\text { kullanımı konusunda neler düşünüyorsun? }\end{array}$ & $\sqrt{ }$ & $\sqrt{ }$ & \\
\hline $\begin{array}{l}\text { 2.Matematikle ilgili hangi TS'leri daha çok } \\
\text { beğendin? Neden? }\end{array}$ & $\sqrt{ }$ & $\sqrt{ }$ & $\sqrt{ }$ \\
\hline
\end{tabular}




\begin{tabular}{|c|c|c|c|}
\hline $\begin{array}{l}\text { 3.Derste kullanılan matematikle ilgili TS'ler } \\
\text { içerisinde gereksiz/anlamsı olduğunu } \\
\text { düşündüğ̈̈n sözler oldu mu? Eğer olduysa } \\
\text { hangi sözleri gereksiz/anlamsız görüyorsun? } \\
\text { Neden? }\end{array}$ & $\sqrt{ }$ & $\sqrt{ }$ & \\
\hline $\begin{array}{l}\text { 4.Öğretmeninin derslerde matematikle ilgili } \\
\text { TS'leri kullanmaya devam etmesini ister } \\
\text { misin? Neden? }\end{array}$ & $\sqrt{ }$ & $\sqrt{ }$ & \\
\hline $\begin{array}{l}\text { 5.Öğgetmenlerin ve öğrencilerin matematikle } \\
\text { ilgili TS'lerden nasıl yararlanabileceklerini } \\
\text { düşünüyorsun? }\end{array}$ & $\sqrt{ }$ & $\sqrt{ }$ & $\sqrt{ }$ \\
\hline $\begin{array}{l}\text { 6.Matematikle ilgili TS'lerden herhangi } \\
\text { birine bahsettin mi? Neden? }\end{array}$ & & $\sqrt{ }$ & \\
\hline
\end{tabular}

Öğrencilerin matematik derslerinde TS'lerin kullanımı ile ilgili görüşlerini tespit etmek ve TS'lere nerelerde yer verdiklerini açığa çıkarmak amacıyla iki farklı devlet okulunda toplam 34 ders saati yapılandırılmamış gözlemler yapılmıştır. Gözlemlerin sadece 11 ders saatinde TS'lere yer verilmiştir. Araştırmacı, matematik derslerini katılımcı olmayan gözlemci sıfatıyla gözlemlemiştir. Yapılan gözlemlerde TS’lerin öğretmenler veya öğrenciler tarafından tahtaya yazıldığı görülmüştür. Öğretmenlerin, öğrencilerin TS'lerle ilgili görüşlerini genellikle dersin başında aldığı ve sözlere yönelik kendi düşüncelerini de ifade ettikleri gözlemlenmiştir. Ayrıca öğrenciler, gözlem yapılmayan zamanlarda da matematik derslerinde TS'lerin kullandığını dile getirmişlerdir.

Araştırmanın amacı ve uzman görüşleri dikkate alınarak, gözlemlerden sonra öğrencilerle boş bir sınıfta mülakatlar da yapılmıştır. Alanyazından faydalanılarak oluşturulan mülakat sorularının kapsam ve yordama geçerliğini sağlamak için alan uzmanı üç akademisyenin görüşlerine başvurulmuştur. Ayrıca 6, 7 veya 8. sınıfta öğrenim gören 10 öğrenci ile pilot çalışma yapılarak ve iki Türkçe öğretmeninin düşünceleri alınarak mülakat sorularına son hali verilmiştir.

Nitel çalışmalarda araştırmanın geçerliğini arttırmak için gözlem ve mülakatların yanında üzerinde çalışılan araştırma problemi ile ilişkili yazılı ve görsel materyaller de kullanılabilir (Yıldırım ve Şimşek 2008). Bu araştırmada, öğrencilerin matematikle ilgili TS'lere nerelerde yer verdiklerini tespit etmek için doküman incelemesinden de yararlanılmıştır. Bu bağlamda panolar, ürün dosyaları, sınıf tahtaları ve öğrenci defterleri incelenmiştir.

\subsection{Verilerin Analizi}

Çalı̧̧manın verileri gözlem, mülakat ve doküman incelemesi aracılığıyla toplanmıştır. Elde edilen nitel veriler, veri üçgenlemesi yapılarak analiz edilmiştir. Bu çalışmada gözlem verilerinin analizinde betimsel analiz, mülakat verilerinin analizinde ise betimsel ve içerik analizi birlikte 
kullanılmıştır. Öğrencilerin mülakat sorularına verdikleri cevapları yorumlama sürecinde gözlem verilerinden yararlanılmıştır. Gözlemlerden sonra öğrencilerle mülakatlar yapılmıştır. Mülakatlar ilk olarak cep telefonu ile kayıt edilmiştir. Ardından ses kayıtları araştırmacı tarafından dinlenmiş, öğrencilerin mülakat sorularına verdikleri yanıtlar ise Word belgelerine yazılarak mülakat dökümleri oluşturulmuştur. Mülakat dökümlerini daha ayrıntıl incelemek ve betimsel analizde tespit edilemeyen kod ve kategorileri belirlemek için içerik analizine başvurulmuştur. İçerik analizi sırasında öncelikle kodlamalar yapılmıștır. İkinci olarak, benzer kodlar bir arada toplanmış ve bu kodları kapsayan kategoriler tespit edilmiştir. Üçüncü olarak, veriler kodlara ve kategorilere göre düzenlenmiştir. Son olarak kategoriler, kodlar ve kodların frekansları tablolar halinde okuyuculara sunulmuş ve tabloların altında öğrencilerin bazı kodlara yönelik cümlelerinden örnekler verilmiştir.

Kodlama sürecinin güvenirliğini sağlamak amacıyla Ö1 ile yapılan mülakat metni araştırmacı tarafından kodlanmış ve oluşturulan kodlar kategoriler altında toplanmıştır. Araştırmacının belirlediği kodlar ve kategoriler başka bir akademisyene verilmiştir. Daha sonra, Ö1'e ait mülakat dökümü üzerinde iki kodlayıcı tarafından kodlanan kodların uyumuna bakılmıştır. Güvenirlik katsayısı [Görüş Birliği/(Görüş Birliği+Görüş Ayrılığı)x100] (Miles ve Huberman, 1994) formülü yardımıyla \%90 olarak hesaplanmıştır. Araştırmacılar uyuşamadıkları kodlar üzerinde tekrar tartışma yapmış ve fikir birliğine varmışlardır.

Dokümanların diğer veri toplama yöntemleri ile kullanılması durumunda karışık bir veri analizine ihtiyaç olmayacağından (Yıldırım ve Şimşek, 2008), bu araştırmada yazılı ve görsel dokümanlar betimsel analiz yöntemi kullanılarak analiz edilmiştir. Dokümanlardan elde edilen veriler, görüşme ve gözlem yoluyla sağlanan verileri destekleme, çürütme ya da bulunan sonuçlara alternatif açıklamalar getirme amacıyla kullanılabilir (Yıldırım ve Şimşek, 2008). Bu sebeple, dokümanlardan sağlanan veriler, gözlem ve mülakat yoluyla toplanan verileri desteklemek amaciyla kullanılmıştır.

\subsection{Sinırlılıklar}

$\mathrm{Bu}$ araştırma, Trabzon'da öğrenim gören 17 ortaokul öğrencisi ile sınırlı olup çalışma kapsamındaki veriler yarı yapılandırılmış mülakattan, yapılandırılmamış gözlemden ve doküman incelemesinden elde edilmiştir. Ayrıca bu çalışma kapsamında sadece iki matematik öğretmeninin dersleri gözlemlenmiştir. Son olarak, bu araştırmada öğrencilerin bilim insanlarının sadece matematik ile ilgili söyledikleri TS'leri nerelerde kullandıkları belirlenmiş ve bu sözlere yönelik görüşleri incelenmiştir. 


\section{BULGULAR}

Araştırmanın amacı doğrultusunda toplanan verilerden elde edilen bulgular, iki başlık altında sunulmuştur.

\section{1.Öğrencilerin Matematikle İlgili TS'lerin Derslerde Kullanımına İlişkin Görüşlerinden Elde Edilen Bulgular}

Tablo 3.Öğrencilerin matematiğe yönelik TS'lerin derslerde kullanımına ilişkin olumlu görüşleri

\begin{tabular}{cll}
\hline Kategori & \multicolumn{1}{c}{ Kodlar } & f \\
\hline & 1.Matematik dersine ilgiyi arttırma & 9 \\
\cline { 2 - 3 } TS'lerin & 2.Matematik dersini eğlenceli hale getirme & 6 \\
\cline { 2 - 3 } Bilisssel ve & 3.Matematiğin gelişen bir bilim olduğunu gösterme & 6 \\
\cline { 2 - 3 } Duyuşsal & 4.Matematik ile ilgili konuları daha anlamlı hale getirme & 5 \\
\cline { 2 - 3 } Öğrenme & 5.Matematiğe farklı perspektiften bakabilmeyi sağlama & 4 \\
\cline { 2 - 3 } Alanlarına & 6.Öğrencileri matematik dersine hazır hale getirme & 2 \\
\cline { 2 - 3 } Katkıları & 7.Matematiğin her yerde olduğunu gösterme & 2 \\
\cline { 2 - 3 } & 8.Matematiksel ve sözel zekâyı geliştirme & 9.Matematikle ilgili yeni bilgiler öğrenmeyi sağlama \\
\cline { 2 - 3 } & &
\end{tabular}

Tablo 3'e bakıldığında, öğrencilerin matematikle ilgili TS'lerin derslerde kullanımına ilişkin en fazla dile getirdikleri olumlu görüşün derse karşı ilgiyi arttırma olduğu görülmektedir. Yapılan gözlemlerde de TS'lerin kullanıldığı matematik derslerinde birçok öğrencinin derse karşı ilgili olduğu gözlemlenmiştir. Öğrencilerin Tablo 3'teki ilk dört koda yönelik verdikleri cevaplardan bazıları aşağıda verilmiştir:

"Ben matematik dersi ile bu kadar ilgilenmezdim. Bu sözler beni matematiğe daha çok çekti. (Ö15)"

"Herkes yapılan yorumların üstüne bir yorum katmıştı. Bir sözde çok değişik tartışma, eleştiri olmuştu. Ders çok eğlenceli geçmişti. (Ö6)”

“...TS'lerde herkes matematiği yüceltmeye çalışlyor. Bu sözlerle matematiğin hiç bitmeyen bir bilim olduğunu daha iyi anladım. (Ö2)”

"Sözler, matematiksel konuları daha anlamlı hale getiriyor... (Ö16)"

Tablo 4.Öğrencilerin matematikle ilgili TS'lerin derslerde kullanımına yönelik olumsuz görüşleri

\begin{tabular}{clr}
\hline Kategori & \multicolumn{1}{c}{ Kodlar } & f \\
\hline \multirow{2}{*}{ TS'lerin Derslerde } & \multicolumn{1}{c}{ 1.TS'ler yorumlanamadı̆̆ında özgüvenin azalması } & 6 \\
\cline { 2 - 3 } $\begin{array}{c}\text { Kullanımına Yönelik } \\
\text { Olumsuz Görüşler }\end{array}$ & 2.Dersi sıkıcı hale getirme & 2 \\
\cline { 2 - 3 } & 3.Derse odaklanamamaya neden olma & 1 \\
\cline { 2 - 3 }
\end{tabular}

Tablo 4 incelendiğinde, öğrencilerin TS'lerin derslerde kullanımına ilişkin en çok ifade ettikleri olumsuz görüşün bazı sözler yorumlanamadığında 
özgüvenin azalması olduğu anlaşılmaktadır. Gözlemler sırasında da kimi TS'ler hakkında yorum yapılamadığında bazı öğrencilerin motivasyonlarının düştüğü gözlemlenmiştir. Öğrencilerin Tablo 4'teki dört koda yönelik belirttikleri cümlelerden bazıları şu şekildedir:

"İlk başta güzeldi. Sözler sayesinde tahta güzel görünüyordu...Bazen sözleri yorumlayamiyordum. Sonra kendime güvenim azallyordu ... (Ö17)”

"Ya uzun sözler oluyor. Bazen slkıllyorum. (Ö11)"

"Bazen söze odaklanlyorum, dersi dinlemiyorum. (Ö12)"

"Yani, biraz ses oldu, gürültü oldu ... Başta bu tarz durumlar oldu ama her zaman böyle değil. (Ö7)"

Tablo 5.Öğrencilerin hakkında olumlu görüşler belirttikleri matematikle ilgili TS'ler

\begin{tabular}{|c|c|c|}
\hline Kategori & TS'ler & $\mathbf{f}$ \\
\hline \multirow{7}{*}{ 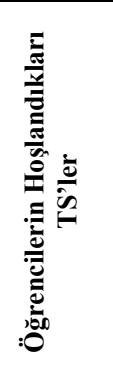 } & $\begin{array}{l}\text { 1.Bir gülün güzelliğindeki sır, onu Yaratan'ın içine sakladığı matematik sanatında } \\
\text { gizlidir. (Leonardo Fibonacci, 1170-1250) }\end{array}$ & 4 \\
\hline & 2.Matematik tüm bilimlerin kraliçesidir. (Carl Friedrich Gauss, 1777-1855) & 1 \\
\hline & $\begin{array}{l}\text { 3.Matematik bilimlerin kraliçesi ve doğanın sırlarının anahtarıdır. (Erdal İnönü, } \\
\text { 1926-2007) }\end{array}$ & 1 \\
\hline & $\begin{array}{l}\text { 4.Matematik, insan zekâsının binlerce yıldır, taş üstüne taş koyarak yükselttiği } \\
\text { yüce bir yap1, görkemli bir anıttır. (Tosun Terzioğlu, 1942-2016) }\end{array}$ & 1 \\
\hline & $\begin{array}{l}\text { 5.Jimnastik insanı güçlendirir, müzik arıtır, matematik mükemmelleştirir. } \\
\text { (Pythagoras, MÖ 580-MÖ 500) }\end{array}$ & 1 \\
\hline & 6.Kâinat matematik dilinde yazılmıştır. (Galile Galileo, 1564-1642) & 1 \\
\hline & 7.Matematikte zekâdan önce sabır gelir. (Cahit Arf, 1910-1997) & 1 \\
\hline
\end{tabular}

Tablo 5 incelendiğinde, öğrencilerin hakkında en çok olumlu görüş ifade ettikleri TS'nin “Bir gülün güzelliğindeki sır, onu Yaratan'ın içine sakladı̆̆ matematik sanatında gizlidir." olduğu anlaşılmaktadır. Yapılan gözlemlerde ve doküman incelemesinde, bazı öğrencilerin bu sözü panoya astığı ve ürün dosyalarına yazdığı görülmüştür. Öğrencilerin Tablo 5'teki birinci TS'ye ilişkin cümlelerinden biri aşağıda verilmiştir:

"Bir gülün güzelliği var ya gülün deseni var ya işte o söze bayıldım. Çünkü bu söz Fibonacci sayılarını kastediyor... (Ö12)”

Tablo 6.Öğrencilerin matematiğe yönelik TS'ler hakkındaki olumlu görüşleri

\begin{tabular}{clc}
\hline Kategori & \multicolumn{1}{c}{ Kodlar } & f \\
\hline & 1.TS'lerden hoşlanma & 6 \\
\cline { 2 - 3 } TS'ler İle İlgili & 2.TS'leri anlamlı bulma & 3 \\
\cline { 2 - 3 } Olumlu Görüş̧ler & 3.TS'lerin önemli olduğunu düşünme & 3 \\
\cline { 2 - 3 } & 4.TS'lerin ilginç olduğunu düşünme & 2 \\
\hline
\end{tabular}


Tablo 6'ya bakıldığında, öğrencilerin matematikle ilgili TS'ler hakkında en fazla belirttikleri olumlu görüşün TS'lerden hoşlanma olduğu görülmektedir. Yapılan gözlemler sırasında da birçok öğrencinin sözlerden hoşlandığını belirten yorumlar yaptığ 1 ve sözleri yorumlarken mutlu olduğu gözlemlenmiştir. Öğrencilerin Tablo 6'daki dört koda yönelik ifade ettikleri cümlelerden bazıları şunlardır:

"Arkadaşlarım bilgisayarda yazmıştı. Bu söz hoşuma gitmişti. $O$ kesirlerle ilgili bir sözdü. (Ö14)"

"Böyle klsa ve öz olması güzel. Yani, 'Matematik tüm bilimlerin kraliçesidir. ' sözü insana anlaml geliyor. (Ö10)”

“... Bilim insanlarının, matematikçilerin hatırası olarak kaldığı için sözlerin önemli olduğunu düşünüyorum. (Ö15)”,

"Bazı sözler de çok ilginç. Mantığımı kullanarak matematikle ilgili yeni şeyler ögreniyorum. (Ö5)"

Tablo 7.Öğrencilerin hakkında olumsuz görüşler belirttikleri matematikle ilgili TS'ler

\begin{tabular}{|c|c|c|}
\hline Kategori & TS'ler & f \\
\hline \multirow{3}{*}{ 吾 } & $\begin{array}{l}\text { 1.Matematik, kökeni deney değil, salt mantık (başka bir deyişle salt akıl) olan bir } \\
\text { disiplindir. (Albert Einstein, 1879-1955) }\end{array}$ & 3 \\
\hline & $\begin{array}{l}\text { 2.Matematikteki zorluklarınızı dert etmeyiniz; benimkilerin sizinkinden daha büyük } \\
\text { olduğuna sizi temin ederim. (Albert Einstein, 1879-1955) }\end{array}$ & 2 \\
\hline & $\begin{array}{l}\text { 3.Öğrenim dönemimde matematik konusuna çok önem vermişimdir. Bundan } \\
\text { hayatımın çeşitli safhalarında başarı elde etmek için faydalanmış olduğumu } \\
\text { söyleyebilirim. Onun için herkes matematik bilgisinin çok gerekli olduğuna } \\
\text { inanmalıdır. (Mustafa Kemal Atatürk, 1881-1938) }\end{array}$ & 2 \\
\hline
\end{tabular}

Tablo 7 incelendiğinde, öğrencilerin hakkında en çok olumsuz görüş belirttikleri TS'nin Albert Einstein'ın matematiğin salt mantıkla ilgili bir disiplin olduğunu belirten sözü olduğu anlaşılmaktadır. Gözlemler sırasında bazı öğrencilerin salt mantığın ne anlama geldiğini bilmediğinden bu sözü yorumlayamadığ 1 görülmüştür. Öğrencilerin Tablo 7'deki üç TS'ye yönelik dile getirdikleri cümlelerden örnekler aşağıda verilmiştir:

"Salt mantık falan bunlar bana göre daha üst seviyede olduğundan, bunu anlamadı̆̆ımdan bu söz bana anlamsız geliyor. (Ö5)" (Ö3)”

"Einstein'in bu sözde ne demek istediğini anlamak bana zor geliyor...

“Atatürk'ün bir sözü vardl. Çok uzundu... (Ö7)”

Tablo 8.Öğrencilerin matematiğe yönelik TS'ler hakkındaki olumsuz görüşleri

\begin{tabular}{ccc}
\hline Kategori & Kodlar & f \\
\hline & 1.Bazı TS'leri anlamada güçlük çekme & 4 \\
\hline
\end{tabular}




\begin{tabular}{clc}
\hline $\begin{array}{c}\text { TS'ler İle } \\
\text { İlgili Olumsuz } \\
\text { Görüşler }\end{array}$ & 2.Bazı TS'leri gereksiz bulma & 3 \\
\cline { 2 - 3 } & 3.Bazı TS'lerin anlamsız olduğunu düşünme & 2 \\
\cline { 2 - 3 } & 4.Bazı TS'lerin uzun olduğunu düşünme & 2 \\
\cline { 2 - 3 } & 5.Bazı TS'lerin ezberlenmesi gerektiğini düşünme & 1 \\
\hline
\end{tabular}

Tablo 8'e bakıldığında, öğrencilerin TS'ler hakkında en fazla belirttikleri olumsuz görüşün bazı sözleri anlamada zorlanma olduğu görülmektedir. Gözlemler esnasında da öğrencilerin bazı sözleri yorumlamada güçlük çektikleri gözlenmiştir. Öğrencilerin Tablo 8'deki ilk iki koda yönelik ifadelerinden örnekler aşağıda sunulmuştur:

"Albert Einstein, çok zeki olduğundan dolayı cümleleri birazcık üst düzey kuruyor. Simdi salt mantık olunca da ben onu kuramayabiliyorum. Yani bazı sözler bana biraz zor geliyor. (Ö5)"

"Bazı sözleri gereksiz buldum. Yine de gereksiz buluyorum ... (Ö14)"

Tablo 9.Öğrencilerin matematiğe ilişkin TS'lerden nasıl yararlanılabilineceğiyle ilgili görüşleri

\begin{tabular}{|c|c|c|}
\hline Kategori & Kodlar & $\mathbf{f}$ \\
\hline \multirow{7}{*}{$\begin{array}{c}\text { TS'lerin } \\
\text { Kullanım } \\
\text { Alanları }\end{array}$} & 1.TS'ler başkalarıyla paylaşılabilir. & 6 \\
\hline & 2.TS'ler panolara asılabilir. & 5 \\
\hline & 3.Derslerde ünlü kişilerin matematiksel kavramlar ile ilgili TS'leri kullanılabilir. & 5 \\
\hline & 4.Sınavlarda TS'leri yorumlamaya yönelik sorular sorulabilir. & 2 \\
\hline & 5.TS'ler defterlere yazilabilir. & 2 \\
\hline & 6.TS’ler ürün dosyalarına yazılabilir. & 2 \\
\hline & 7.TS'ler ile ilgili metin yazılabilir. & 1 \\
\hline
\end{tabular}

Tablo 9'a bakıldığında, öğrencilerin TS'lerin farklı alanlarda kullanımına yönelik yedi görüş belirttikleri görülmektedir. Yapılan gözlemlerde de birçok öğrencinin TS'leri panolara astı̆̆ı; ürün dosyalarına, defterlerine ve tahtalara yazdığı gözlemlenmiştir. Öğrencilerin Tablo 9'daki ilk üç koda yönelik cümlelerinden bazıları şöyledir:

"Ben mesela anneme anlatıyordum işte...tahtaya böyle sözler falan yazdı̆̆ımızı. O zaman matematikle ilgili hatırladiğım sözleri söylemişstim. (Ö11)"

"Mesela okulun girişinde veya sinıflarda büyük panolar oluyor. Bu panolarda matematikle ilgili sözler olabilir. (Ö17)"

"Yani ilk derse girdiğimiz gibi değil de onun sirası geldi mi yani matematiksel kavramlarla ilgili bir şey yaptılar mı onunla ilgili sözü söylerdim... (Ö4)" 


\section{2. Öğrencilerin Matematiğe Yönelik TS'leri Derslerde Nerelerde Kullandıklarına İlişskin Elde Edilen Bulgular}

Tablo 10.Öğrencilerin panolara astıkları matematikle ilgili TS'ler

\begin{tabular}{lcc}
\multicolumn{1}{c}{ TS'ler } & $\begin{array}{c}\text { 6. } \\
\text { Sinıf }\end{array}$ & $\begin{array}{c}\text { 7. } \\
\text { Sinıf }\end{array}$ \\
\hline 1.Matematikle ifade edebiliyorsanız, bilginiz doyurucudur. (Lord Kelvin, 1824-1907) & + & \\
\hline $\begin{array}{l}\text { 2.Hayat sadece iki şey için güzel: Matematiği keşfetme ve öğretme... (Simeon-Denis } \\
\text { Poisson, 1781-1840) }\end{array}$ & + & \\
\hline 3.Dünyadaki en masum uğraş, matematiktir. (Godfrey Harold Hardy, 1877-1947) & + \\
\hline 4.Kâinat matematik dilinde yazılmıştır. (Galile Galileo, 1564-1642) & + \\
\hline 5.Matematik tüm bilimlerin kraliçesidir. (Carl Friedrich Gauss, 1777-1855) & + \\
\hline 6.Matematik de resim, müzik gibi bir sanat dalıdır. (Cahit Arf, 1910-1997) & + \\
\hline $\begin{array}{l}\text { 7.Bir gülün güzelliğindeki sır, onu Yaratan'ın içine sakladığı matematik sanatında } \\
\text { gizlidir. (Leonardo Fibonacci, 1170-1250) }\end{array}$ & + \\
\hline
\end{tabular}

+: TS'lerin belirtilen sınıf düzeyinde kullanıldığını göstermektedir.

Tablo 10 incelendiğinde, 6. ve 7. sınıftaki öğrencilerin panolara kısa TS'ler asma eğiliminde oldukları ve 8. sınıflardaki panolara TS asılmadığı görülmektedir.

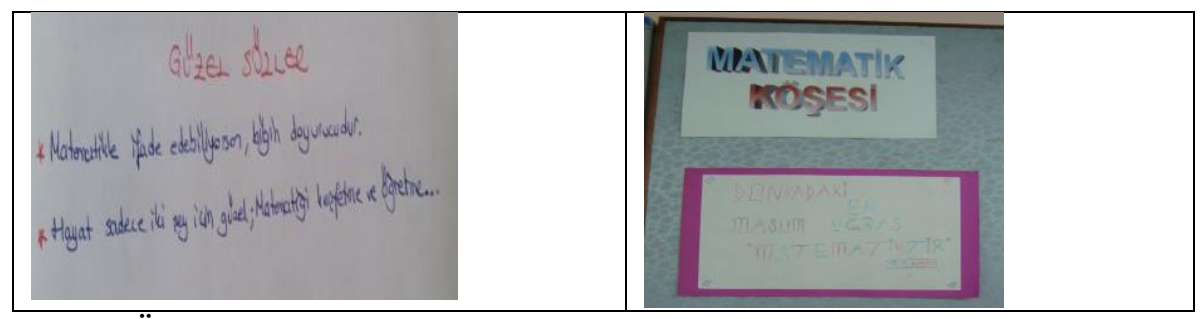

Şekil 1.Öğrencilerin panolara astıkları TS’lerden örnekler

Şekil 1'e bakıldığında, öğrencilerin panolara matematik bilgisinin öneminden, matematiksel keşiften ve matematiğin masum bir uğraş alanı olduğundan bahseden TS'ler astıkları anlaşılmaktadır.

Tablo 11.Öğrencilerin tahtalara yazdıkları matematiğe yönelik TS'ler

\begin{tabular}{|c|c|c|c|}
\hline TS'ler & $\begin{array}{c}6 . \\
\text { Sinif }\end{array}$ & $\begin{array}{c}7 . \\
\text { Sinif }\end{array}$ & $\begin{array}{c}8 . \\
\text { Sinif }\end{array}$ \\
\hline 1.Kâinat matematik dilinde yazılmıştır. (Galile Galileo, 1564-1642) & + & + & + \\
\hline 2.Matematik de resim, müzik gibi bir sanat dalıdır. (Cahit Arf, 1910-1997) & & + & \\
\hline $\begin{array}{l}\text { 3.Bir matematikçi sanmaz; fakat bilir. İnandırmaya çalışmaz; çünkü ispat eder. } \\
\text { (Henri Poincare, 1854-1912) }\end{array}$ & & + & \\
\hline $\begin{array}{l}\text { 4.Matematiğin ilerlemesi ve mükemmelliği devletin refahıyla yakından } \\
\text { ilişkilidir. (Napoleon Bonaparte, 1769-1821) }\end{array}$ & & + & \\
\hline $\begin{array}{l}\text { 5.Ruhen bir şair olmadan, bir matematikçi olmak imkânsızdır. (Sonya } \\
\text { Kovalevskaya, 1850-1891) }\end{array}$ & & & + \\
\hline
\end{tabular}


Tablo 11 incelendiğinde, 7. sınıflarda tahtaya yazılan TS sayısının daha fazla olduğu görülmektedir. Ayrıca kâinatın matematik diliyle yazıldığını belirten bir numaralı sözün 6., 7. ve 8. sinıflarda kullanıldığı anlaşılmaktadır.

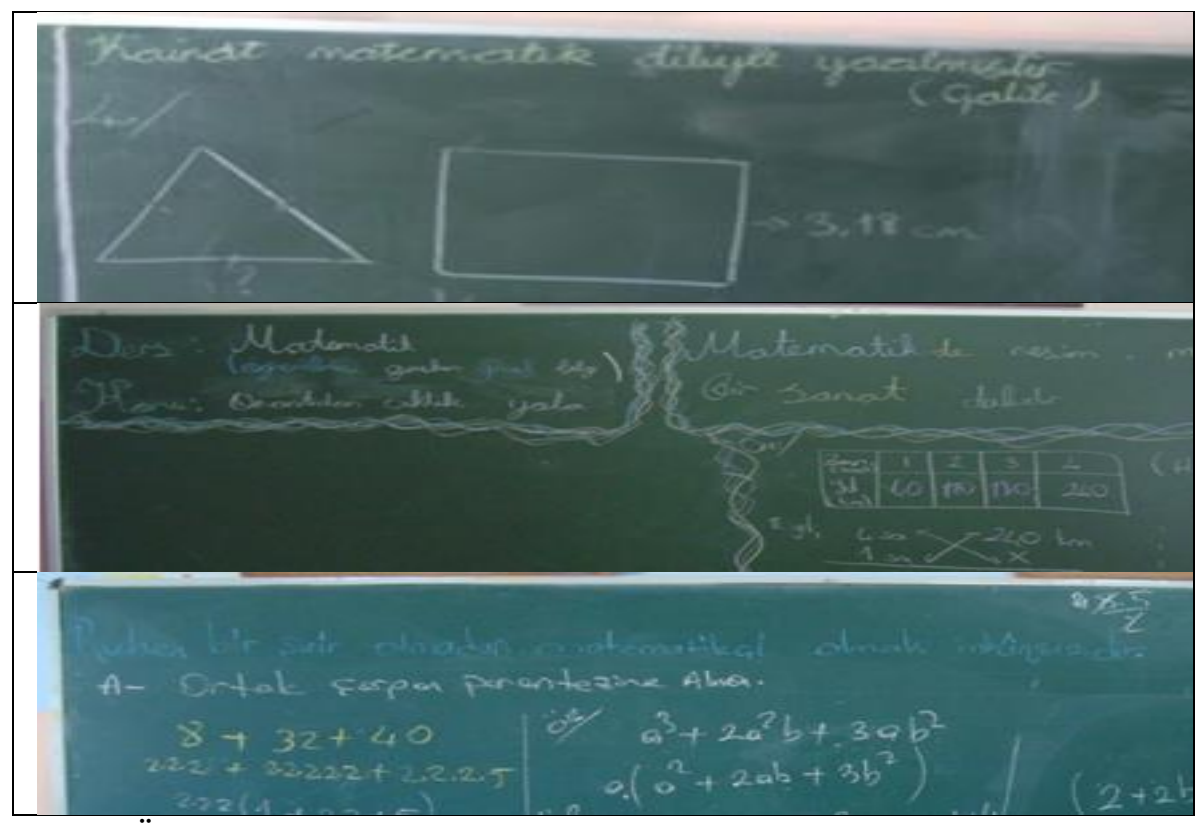

Şekil 2.Öğrencilerin tahtalara yazdıkları 1, 2 ve 5 numaralı TS'ler

Şekil 2'ye bakıldığında, tahtaya yazılan sözlerin işlenilen konularla ilgili olmadığı görülmektedir.

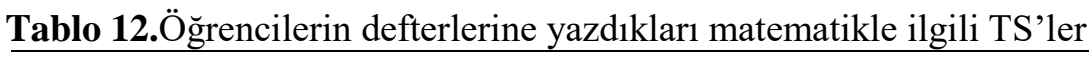

\begin{tabular}{|c|c|c|c|}
\hline TS'ler & $\begin{array}{c}6 . \\
\text { Sinıf }\end{array}$ & $\begin{array}{c}7 . \\
\text { Sinif }\end{array}$ & $\begin{array}{c}8 . \\
\text { Sinif }\end{array}$ \\
\hline $\begin{array}{l}\text { 1.Matematik pozitif tabiat bilimlerine, başka hiçbir türlü elde edemeyecekleri bir } \\
\text { güvenlik temin eder. (Albert Einstein, 1879-1955) }\end{array}$ & + & & \\
\hline 2.Matematikte zekâdan önce sabır gelir. (Cahit Arf, 1910-1997) & + & & + \\
\hline 3.Kâinat matematik dilinde yazılmıştır. (Galile Galileo, 1564-1642) & + & + & + \\
\hline $\begin{array}{l}\text { 4.Matematiğin ilerlemesi ve mükemmelliği devletin refahıyla yakından } \\
\text { ilişkilidir. (Napoleon Bonaparte, } 1769-1821 \text { ) }\end{array}$ & & + & + \\
\hline $\begin{array}{l}\text { 5.Bir matematikçi sanmaz; fakat bilir. İnandırmaya çalışmaz; çünkü ispat } \\
\text { eder. (Henri Poincare, 1854-1912) }\end{array}$ & & + & \\
\hline 6.Matematik tüm bilimlerin kraliçesidir. (Carl Friedrich Gauss, 1777-1855) & & + & + \\
\hline $\begin{array}{l}\text { 7.Matematikle ifade edebiliyorsanız, bilginiz doyurucudur. (Lord Kelvin, } \\
\text { 1824-1907) }\end{array}$ & & & + \\
\hline $\begin{array}{l}\text { 8.Dünyadaki en masum uğraş, matematiktir. (Godfrey Harold Hardy, 1877- } \\
\text { 1947) }\end{array}$ & & & + \\
\hline $\begin{array}{l}\text { 9.Ruhen bir şair olmadan, bir matematikçi olmak imkânsızdır. (Sonya } \\
\text { Kovalevskaya, 1850-1891) }\end{array}$ & & & + \\
\hline $\begin{array}{l}\text { 10.Matematik bilimlerin kraliçesi ve doğanın sırlarının anahtarıdır. (Erdal } \\
\text { İnönü, 1926-2007) }\end{array}$ & & & + \\
\hline
\end{tabular}




\begin{tabular}{|c|c|}
\hline $\begin{array}{l}\text { 11.Hiçbir araştırma, matematik ispattan geçmedikten sonra bilim adını } \\
\text { almaya layı olamaz. (Leonardo Da Vinci, 1452-1519) }\end{array}$ & + \\
\hline $\begin{array}{l}\text { 12.Matematik, kökeni deney değil, salt mantık (başka bir deyişle salt akıl) } \\
\text { olan bir disiplindir. (Albert Einstein, 1879-1955) }\end{array}$ & + \\
\hline $\begin{array}{l}\text { 13.Bugün, olasıllk hesabının girmediği bir olay iyi anlaşılmış sayılmaz. } \\
\text { (Richard Von Mises, 1883-1953) }\end{array}$ & + \\
\hline $\begin{array}{l}\text { 14.Çoğu bilimde bir nesil, başka bir neslin yaptı̆ı̆ını yıkar veya bozar. } \\
\text { Matematikte ise, her nesil eski yapıya yeni bir hikâye katar. (Hermann } \\
\text { Hankel, 1839-1873) }\end{array}$ & + \\
\hline $\begin{array}{l}\text { 15.Matematik en açık olanı en açık yolla kanıtlama işidir. (George Polya, } \\
\text { 1887-1985) }\end{array}$ & + \\
\hline 16.Tek kesinlik, mantıklı bir olasılıktır. (Edgar Watson Howe, 1853-1937) & + \\
\hline $\begin{array}{l}\text { 17.Her keşif, biçimsel olarak matematikseldir. Çünkü elimizde başka hiçbir } \\
\text { yol gösterici yoktur. (Charles Darwin, 1809-1882) }\end{array}$ & + \\
\hline $\begin{array}{l}\text { 18.Matematik, bilgilerin en eskisi, en sadesi ve en mükemmelidir. (Hamit } \\
\text { Dilgan, 1901-1976) }\end{array}$ & + \\
\hline $\begin{array}{l}\text { 19.Matematik, gerekli sonuçları çıkaran bilimdir. (Benjamin Pierce, 1757- } \\
\text { 1839) }\end{array}$ & + \\
\hline $\begin{array}{l}\text { 20.Matematik, bildiği ile yetinmeyip araştıran, bulduğu ile kalmayıp doğruyu } \\
\text { arayan insan zekâsının ürünüdür. (Evariste Galois, 1811-1832) }\end{array}$ & + \\
\hline $\begin{array}{l}\text { 21.Matematiğin hiçbir dalı yoktur ki, ne kadar soyut olursa olsun, bir gün } \\
\text { gerçek dünyada uygulama alanı bulamasın. (Nikolai Ivanovich Lobachevsky, } \\
\text { 1792-1856) }\end{array}$ & + \\
\hline
\end{tabular}

Tablo 12 incelendiğinde, öğrencilerin olasılıkla, mantıkla, ispatla, sabırla, matematiğin önemi ve uygulama alanlarıyla ilgili birçok TS'yi defterlerine yazdıkları anlaşılmaktadır.

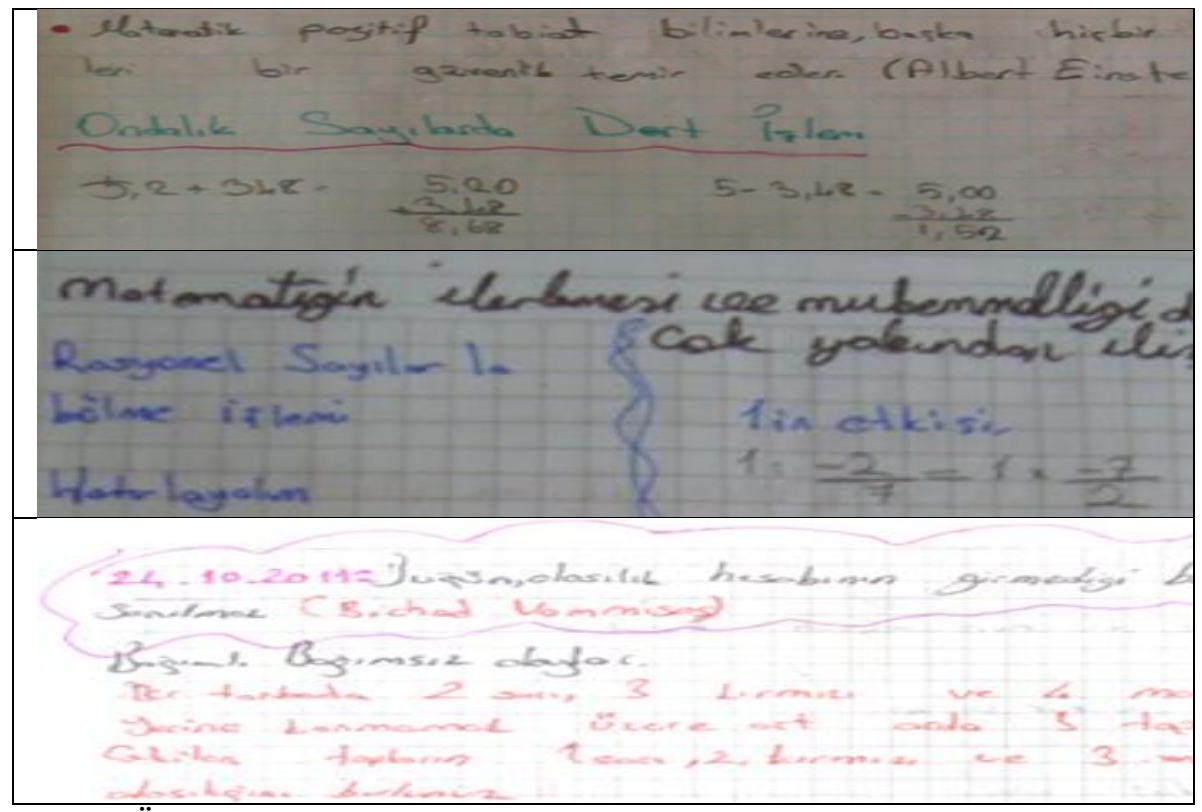

Şekil 3.Öğrencilerin defterlerine yazdıkları 1, 4 ve 13 numaralı TS'ler 
Şekil 3'e bakıldığında, öğrencilerin defterlerine yazdıkları 13 numaralı sözün işledikleri olasılık konusuyla alakalı olduğu görülmektedir.

Tablo 13.Öğrencilerin ürün dosyalarına yazdıkları matematikle ilgili TS'ler

\begin{tabular}{lcc}
\multicolumn{1}{c}{ TS'ler } & $\begin{array}{c}\text { 6. } \\
\text { Sinıf }\end{array}$ & $\begin{array}{c}\text { 7. } \\
\text { Sinıf }\end{array}$ \\
\hline 1.Matematikte zekâdan önce sabır gelir. (Cahit Arf, 1910-1997) & + & \\
\hline $\begin{array}{l}\text { 2.Bir gülün güzelliğindeki sır, onu Yaratan'ın içine sakladığı matematik sanatında } \\
\text { gizlidir. (Leonardo Fibonacci, 1170-1250) }\end{array}$ & + \\
\hline $\begin{array}{l}\text { 3.Hayat sadece iki şey için güzel: Matematiği keşfetme ve öğretme... (Simeon-Denis } \\
\text { Poisson, 1781-1840) }\end{array}$ & + \\
\hline $\begin{array}{l}\text { 4.Kâinat matematik dilinde yazılmışttr. (Galile Galileo, 1564-1642) } \\
\text { 5.Bir matematikçi sanmaz; fakat bilir. İnandırmaya çalışmaz; çünkü ispat eder. (Henri } \\
\text { Poincare, 1854-1912) }\end{array}$ & + \\
\hline
\end{tabular}

Tablo 13 incelendiğinde, ürün dosyalarına TS yazma işlemini daha çok 7. sınıftaki öğrencilerin yaptıkları ve 8. sınıflarda öğrenim gören öğrencilerin ürün dosyalarında TS'lere yer vermedikleri anlaşılmaktadır. Ayrıca öğrencilerin ürün dosyalarına, defterlerine yazdıkları sözler dışında yeni TS'ler (2 ve 3 numaralı sözler) de yazdıkları görülmektedir.

\section{Bir güLÜNGÏZZLLiĞínDEki SIR: ONU YARATAV'IN ICICINE SAKLADIĞI MATEMATIKK SANATINDA GiZLLIDIR.}

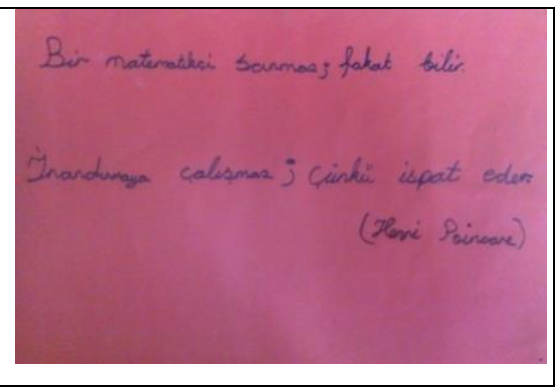

Şekil 4.Öğrencilerin ürün dosyalarına yazdıkları 2 ve 5 numaralı TS'ler

Şekil 4'teki TS'lerin matematiğin doğada kullanımına ve ispatın önemine yönelik olduğu anlaşılmaktadır.

\section{TARTIŞMA, SONUÇ ve ÖNERILER}

Ortaokul öğrencilerinin matematikle ilgili TS'lerin derslerde kullanımına yönelik görüşlerinin ve TS'lere nerelerde yer verdiklerinin belirlenmesinin amaçlandığı bu çalışmada, bulgulara dayalı olarak yapılan tartışma sonucunda aşağıdaki sonuçlara varılmıştır:

Öğrencilerin matematikle ilgili TS'lere ve TS'lerin derslerde kullanımına yönelik genel olarak olumlu görüssler belirttikleri belirlenmiştir. Öğrencilerin TS'lerden hoşlandıkları; TS'leri anlamlı, önemli ve ilginç buldukları ortaya çıkmıştır. Bu durum, TS'lerin öğrencilerin ilgilerini çektiği şeklinde yorumlanabilir. Yapılan gözlem ve mülakatlarda, öğrencilerin 
TS'lerin derslerde kullanımı ile ilgili farklı olumlu görüşler ifade ettikleri görülmüştür. Öğrencilerin en çok dile getirdikleri olumlu görüşlerin derse ilgiyi arttırma (Yakıncı vd., 2013), dersi eğlenceli hale getirme (Atmaca, 2007; Çağlayan, 2006; Yakıncı vd., 2013), öğrencilere matematiğin gelişen bir bilim olduğunu gösterme, konuları daha anlamlı hale getirme olduğu açığa çıkmıştır. Bu bulgular, TS’lerin birçok farklı amaç için derslerde öğretim aracı olarak kullanılabileceğini göstermektedir.

$\mathrm{Bu}$ araştırma, öğrencilerin matematikle ilgili TS'lerin derslerde kullanımına ilişkin olumsuz görüşler de belirttiklerini ortaya çıkarmıştır. Sözler yorumlanamadığında özgüvenin azalması, bu olumsuz düşünceler arasında birinci sırada yer almaktadır. Alan yazında da özgüvenin öğrenciler üzerinde önemli bir etkisinin olduğu birçok çalışmada (Horton, 2011; Lingard, 2000; Panasuk ve Horton, 2012; Siu, 2007; Smestad, 2000) dile getirilmektedir. Özgüvene etki eden faktörlerden biri de bireylerin okuma alışkanlıkları olabilir (Öztemiz, Bitri ve Yılmaz, 2016; Rizopoulos ve Wolpert, 2004). Dolayısıyla, öğrencilerin TS'leri yorumlarken öğretmen tarafindan zaman zaman motive edilmesi ve kitap okumaya yönlendirilmesi gerekmektedir.

Bazı öğrencilerin matematiğe yönelik kimi TS'ler için olumsuz görüşler ifade ettikleri açığa çıkmıştır. Sınıf içinde yapılan gözlemlerde ve ders sonlarında yapılan mülakatlarda öğrencilerin bazı TS'leri anlamada güçlük çektikleri; kimi TS'leri de gereksiz, anlamsız ve uzun buldukları görülmüştür. Öğrencilerin karşılaştıkları bu durumlar karşısında TS'lere ilgi göstermeyecekleri unutulmamalıdır. Bu bağlamda, öğrencilerin TS'lerin önemi, TS'lerle ilgili etkinliklerdeki rolleri ve görevleri gibi konularda bilgilendirilmeleri gerektiği anlaşılmaktadır.

Matematiğe yönelik TS'lerden derslerde nasıl yararlanılacağıyla ilgili olarak öğrencilerin en fazla belirttikleri görüşün, TS'lerin başkalarıyla paylaşılmas1 olduğu görülmüştür. Bu husus, Socrates'in "Bir şeyi gerçekten bilmek, onu anlatmakla olur." sözüyle açıklanabilir (Yıldız, 2013). Öğrencilerin TS'lere ilişkin bilgilerindeki artış, sözleri paylaşma konusundaki cesaretlerini arttırmış olabilir. Dolayısıyla, öğrencilerin TS'lerle alakalı elde ettikleri bilgi ve deneyimi başkalarıyla paylaşmak istedikleri anlaşılmaktadır.

$\mathrm{Bu}$ çalışmada, matematikle ilgili TS'lerin öğrencilere yeni alternatifler sunduğu da tespit edilmiştir. Bu bağlamda, birçok öğrencinin TS'leri panolara astıkları, defterlerine not ettikleri, tahtalara ve ürün dosyalarının kapaklarına yazdıkları görülmüştür. Yapılan doküman incelemesi ve gözlemler bu bulguları destekler niteliktedir. Bu durum, öğrencilerin TS'lerin kendilerine sağladığ 1 farklı alternatifleri görmelerinden veya öğretmenlerinin bu süreç boyunca kendilerine rehberlik etmelerinden kaynaklanmış olabilir.

$\mathrm{Bu}$ araştırmanın sonuçlarına dayalı olarak oluşturulan öneriler aşağıda verilmiştir: 
-Öğretmenlerin matematik derslerinde uzun TS'ler yerine daha kısa ve anlaşılır sözleri tercih etmeleri önerilmektedir.

-Öğrencilerin TS'lerde geçen bazı kelimelerin anlamlarını bilmediklerinden sözleri yorumlayamadıkları görülmüştür. Bu bağlamda, öğrencilerin kelime dağarcıklarını arttırmak ve okuduklarını daha kolay anlamalarını sağlamak için öğrencilere okumanın önemi ile ilgili bilgiler verilerek onların okuma konusundaki bilinç düzeyi arttırılabilir. Ayrıca, ailelerin ve öğretmenlerin öğrencileri daha fazla kitap okumaya yönlendirmeleri faydalı olabilir.

-Bazı öğrencilerin TS'lerin kimilerini gereksiz ve anlamsız görmelerinin, derslerde TS'lerin kullanımını olumsuz etkilediği görülmüştür. $\mathrm{Bu}$ nedenle, öğrencilere TS'lerin önemine yönelik bilgilendirme yapılması önerilmektedir.

-Bu çalışma kapsamındaki öğrencilerin de belirttiği gibi, TS'ler panolara asılabilir, defterlere ve ürün dosyalarına yazdırılabilir, öğrencilerden TS'lere ilişkin metin yazmaları istenebilir ve öğrencilere sınavlarda TS'leri yorumlamaya yönelik sorular sorulabilir.

-Öğrencilere matematikle ilgili TS'ler bulmaları ve zaman zaman kendilerinin de matematiğe yönelik basit sözler üretmeleri önerilmektedir.

-TS'lerin matematik derslerindeki kullanımını arttırmak için öğretim programlarına TS'lerle ilgili kazanımlar, matematik kitaplarına ise TS'lere yönelik etkinlikler, proje ve performans konuları eklenebilir. Ayrıca merkezi sinavlarda TS'lere yönelik sorular sorulabilir.

-Eğitim fakültelerinde öğretmen adaylarına alan eğitimi derslerinde TS'lerden nasıl yararlanacaklarına yönelik bilgiler verilmesi ve öğretmenlik uygulamalarında TS'lerle ilgili etkinlikler yaptırılması matematik derslerinde TS'lerin kullanımını arttırabilir.

-Öğretmenlerin, ortaöğretim ve lisans öğrencilerinin TS'lerin derslerde kullanımıyla ilgili görüssleri de alınabilir. Böylece, öğretmenlerin ve öğrencilerin derslerde TS'lerden nasıl yararlanabileceği konusunda bilgi ve tecrübelerini arttırmalarına yardımcı olunabilir.

Özetle; derslerde TS'lere yer verilirse, öğrencilerin matematik dersine ilgileri artacak, dersler daha zevkli hale gelecek, öğrenciler matematiğin gelişen bir bilim olduğunu daha iyi görebileceklerdir. Buna göre, öğretim programlarında matematiksel kavramlarla ilgili TS'lerin eklenmesi derslerin tarihsel olarak zenginleşmesi açısından faydalı olabilecektir. Ayrıca öğrencilerin TS'leri öğrenmeleri ve kullanmaları özellikle kimlik oluşumunda öğrenciler için bir firsat olabilir. Bu sebeple, öğretmenler bu konuda daha duyarlı olabilirler ve öğretim uygulamalarını TS'lere yer vererek zenginleştirebilirler. 


\section{KAYNAKCA}

Alkan, H. (Ed.) (2007). Ortaöğretim matematik 9. sınıf ders kitabı. İstanbul: Milli Eğitim Bakanlığı Yayınları.

Atmaca, A. (2007). Tarihe mal olmuş popüler sözler. İstanbul: Nesil Yayınları.

Aydın, N., \& Beşer, Ş. (2009). İlköğretim matematik 8 ders kitabı. Ankara: Aydın Yayıncılık ve Eğitim Hizmetleri.

Bozkurt, A., Ak, S., Erdoğan, A., \& Şahin, İ. (2008). Ortaöğretim 9. sınıf matematik. Ankara: Ekoyay Yayıncilık.

Cohen, L., \& Manion, L. (1994). Research methods in education (4th Ed.). New York: Rutledge.

Çağlayan, A. (2006). Eğitimcilere bilgece sözler. İstanbul: Gülhane Yayınları.

Çepni, S. (2007). Araştırma ve proje çalışmalarına giriş (2. Baskı). Trabzon: Celepler Matbaacilik.

Durmuş, S. (Ed.) (2010). Illköğretim 8 matematik ders kitabı. Ankara: ÖzkanGazetecilik.

Ertan, M. (2012). Tarihi sözler antolojisi (8. Baskı). Ankara: Afşar Matbaacılık.

Göğün, Y. (2008). İlköğretim matematik 6. sınıf ders kitabı. Ankara: Özgün Matbaacilık.

Hatısaru, V. (2009, Kasım). Ortaöğretim ögrencilerinin matematiğe yönelik düşünceleri: Kompozisyon yazma uygulaması. 8. Matematik Sempozyumu Sergi ve Şenlikleri, TOBB Ekonomi ve Teknoloji Üniversitesi, Ankara.

Horton, L. B. (2011). High school teachers' perceptions of the inclusion of history of mathematics in the classroom. Unpublished doctoral dissertation, United States of America: University of Massachusetts Lowell.

Işık, F., \& Kopuz, B. (2005). Geliştiren sözler (2. Baskı). İstanbul: Armoni Yayıncılık.

Kaptan, E. (2009). Ortaöğretim matematik 10 ders kitabı. Ankara: Paşa Yayıncılık.

Karakuyu, E., \& Bağc1, O. (2014). Ortä̈ğretim matematik 9 ders kitabı. Ankara: Dikey Yayıncılık.

Lingard, D. (2000). UK: A new dimension in educating mathematics teachers. In J. Fauvel \& J. Van Maanen (Eds.), History in mathematics education: The ICMI study (pp. 117-122). London: Kluwer Academic Publishers.

McMillan, J. H., \& Schumacher, S. (2006). Research in education: Evidence-based inquiry (6th Ed.). Boston: Pearson.

Miles, M. B., \& Huberman, A. M. (1994). Qualitative data analysis. Thousand Oaks, CA: Sage.

Öztemiz, S., Bitri, E., \& Yılmaz, B. (2016). Ankara'da yaşayan sosyal bireylerin okuma alışkanlıkları üzerine bir araştırma. Eğitim Bilim Toplum Dergisi, 14(54), 152-171.

Panasuk, R. M., \& Horton, L. B. (2012). Integrating history of mathematics into curriculum: What are the chances and constraints? International Electronic Journal of Mathematics Education, 7(1), 3-20. 
Rizopoulos, L. A., \& Wolpert, G. (2004). An overview of the techniques used to develop the literacy skills of adolescents with developmental delays. Education, 125(1), 130-136.

Siu, M. K. (2007). No, I don't use history of mathematics in my class. Why? In F. Furinghetti, S. Kaijser, \& C. Tzanakis (Eds.), Proceedings of the History and Pedagogy of Mathematics 2004 \& European Summer University 4 (pp. 268277). Uppsala: Uppsala University.

Smestad, B. (2000). History of mathematics in Norwegian textbooks. Ninth International Congress on Mathematics Education, Tokyo, Japan.

Swetz, F. J. (1994). Learning activities from the history of mathematics. J. Weston Walch Publisher.

Türk Dil Kurumu Sözlüğü. (2011). Türkçe sözlük. Ankara: Türk Dil Kurumu Yayınlar1.

Yakıncı, C., Yakında, H., \& Akın, K. (2013). Tıp eğitiminde özdeyişlerin gücü. Çocuk Sağlığl ve Hastalıkları Dergisi, 56, 143-150.

Yaşar, Ş., \& Girmen, P. (2012). İlköğretim öğrencilerinin Türkçe dersi konuşma ve yazma sürecinde metaforlardan yararlanma durumları. Mersin Üniversitesi Ĕ̈itim Fakültesi Dergisi, 8(3), 13-23.

Yıldırım, A., \& Şimşek, H. (2008). Sosyal bilimlerde nitel araştırma yöntemleri (6. Baskı). Ankara: Seçkin Yayıncılık.

Yıldız, C. (2013). Ortaokul matematik öğretmenlerinin matematik tarihini derslerinde kullanma durumlarının incelenmesi: HİE'den yansımalar. Yayınlanmamış doktora tezi, Trabzon: Karadeniz Teknik Üniversitesi, Eğitim Bilimleri Enstitüsü.

Yıldız, C., \& Taşkın, D. (2011, April). What does history talk about mathematics: Case of composition study. Paper presented at the Second International Conference on New Trends in Education and Their Implications, Porto Bello Hotel, Antalya. 


\section{Introduction}

\section{EXTENDED ABSTRACT}

People communicate with each other and the outer world with the help of words and sayings (Yaşar and Girmen, 2012). Saying is the mirror of a society. Beautiful and meaningful sayings will add many beauties to people. Saying could be defined as a word, remark and an expression that describes a thought perfectly (Turkish Language Association, 2011). A person may sometimes need tens of sayings while describing an emotion or a thought. Sometimes, sayings could be so beautiful that they could change the life perspective and take hold of people for a long time as they efficiently describe opinions (Işık and Kopuz, 2005). Thus, people frequently use beautiful sayings.

Sentences that describe an emotion or a thought in a short and an efficient way and are generally not anonymous are called epigraph, wise saying, dictum, courteous word, exemplary word, aphorism, motto (Yakıncı, Yakında, and Akın, 2013). In math, these sentences are called "Historical Sayings (HS)". HSs comprise an educational material that may leave an important impression on students and contribute to the development of historical empathy when used appropriately and timely. As HSs historically enrich the flow of lessons (Swetz, 1994), it is required to use the mathematical HSs of scientists that are considered great and important in mathematics lessons. The mathematical HSs of these people are a role model for students and thus, they may prepare students for mathematics lessons.

Renewing and updating of curricula has increased the importance of HSs in books (Alkan, 2007; Aydın and Beşer, 2009; Bozkurt, Ak, Erdoğan, and Şahin, 2008; Durmuş, 2010; Göğün, 2008; Kaptan, 2009; Karakuyu and Bağc1, 2014), which reveals the necessity of using mathematical HSs in classes. Examining the relevant literature; there were only two studies that have been found on the use of HSs in math lessons (Hatısaru, 2009; Yıldız and Taşkın, 2011). In these studies, it is observed that HSs are used for revealing the opinions of middle and secondary school students about math class. It is recommended to involve mathematical HSs in lessons more frequently. Because these sayings could make mathematics lessons more entertaining, increase the general culture levels of students concerning mathematics, and cause them to love mathematics. It is also recommended to hand the emotions and thoughts of the owners of history's important mathematical sayings down the next generations, receive the opinions of students about these sayings and determine where they use them. As a result of the literature review, no studies were encountered which examined the opinions of students about the use of mathematical HSs in classes and where they use the HSs. Thus, this study has been conducted for the purpose of scientifically revealing the present condition, filling a gap in the field and guiding future studies.

\section{Method}

Case study method was used in this study. In order to reveal the variety of individuals that would be a side of the problem in the study at the maximum level (McMillan and Schumacher, 2006; Yıldırım and Şimşek, 2008); maximum variation sampling was preferred in the study. Study participants consisted of 17 voluntary students that were studying at two different public schools in Trabzon.

In the study, the data were collected with the help of unstructured observation, semistructured interview, and document examination. In order to determine the opinions of students about the use of HSs in math classes and where they used HSs; unstructured observations were made for totally 34 course hours at two different middle schools. The researcher observed math classes as a non-participant observer. Additionally, it was observed that the teachers generally received the opinions of students about HSs at the beginning of classes and also expressed their own opinions concerning the sayings. 
Taking the study objective and expert opinions into consideration; interviews were also conducted with students in an empty classroom after observations. Opinions of three academicians that were expert in the domain were asked for the purpose of providing the content and prediction validity of interview questions, which were formed by using the literature. Besides, the interview questions were finalized by conducting a pilot study with 10 students studying in the 6th, 7th or 8th grade and receiving the opinions of two Turkish teachers. In this study, the method of document examination was used for the purpose of determining where students used the mathematical HSs.

The data were analyzed by using descriptive and content analysis. While observation data were analyzed by using descriptive analysis; interview data were analyzed by using descriptive and content analysis. Written and visual documents, on the other hand, were analyzed by using the descriptive analysis method.

\section{Result and Discussion}

It was concluded that students generally had positive opinions about mathematical HSs and the use of mathematical HSs in classes. Students were observed to like HSs and find them significant, important, and interesting. This condition may signify that HSs attract the attention of students. As a result of observations and interviews, it was determined that students expressed different positive opinions about the use of HSs in classes. Positive opinions that were frequently expressed by students were as follows; increasing the interest in the lesson (Yakıncı et al., 2013), making the lesson more entertaining (Atmaca, 2007; Çağlayan, 2006; Yakinc1 et al., 2013), showing the students math as a developing science, and making the subjects more meaningful. These findings show that HSs could be used as an educational instrument in classes for a great variety of purposes.

As a result of this study, it was determined that students had negative opinions about the use of mathematical HSs in classes at some certain points. Having a reduced self-confidence in case of the failure of interpreting sayings is among the primary negative thoughts. Similarly, literature involves a number of studies which suggest that self-confidence has an important effect upon students (Horton, 2011; Lingard, 2000; Panasuk and Horton, 2012; Siu, 2007; Smestad, 2000). One of the factors affecting the self-confidence may be reading habits of individuals (Öztemiz, Bitri, and Y1lmaz, 2016; Rizopoulos and Wolpert, 2004). Thus, students need to be motivated and guided for reading by their teachers from time to time while interpreting the HSs.

It is observed that some students express negative opinions about some of the mathematical HSs. As a result of observations that were made in classes and interviews that were conducted at the end of lessons; it was observed that students had a difficulty in comprehending some HSs and considered them unnecessary, meaningless, and long. It should be remembered that students will not show any interest in HSs under these conditions. In order to overcome these problems, it is required to inform students about the importance of HSs, as well as their roles and tasks in HS activities.

Concerning how to use mathematical HSs in classes; students generally emphasized the necessity for sharing HSs with others, which could be explained with Socrates' famous saying (Y1ldz, 2013), "The best way of knowing something is telling it". Increase in the knowledge of students concerning HSs might have increased their courage of sharing the sayings. Therefore, students apparently wanted to share their knowledge and experiences concerning HSs with others.

This study has also revealed new alternatives presented by mathematical HSs to students. In this context, it was observed that a number of students hung HSs on panels, wrote them down in their notebooks, on the covers of product files and boards. The document examination and observations also support these findings. This condition could be associated with students' realization of different alternatives presented to them by HSs or teachers' guidance throughout this process. 